
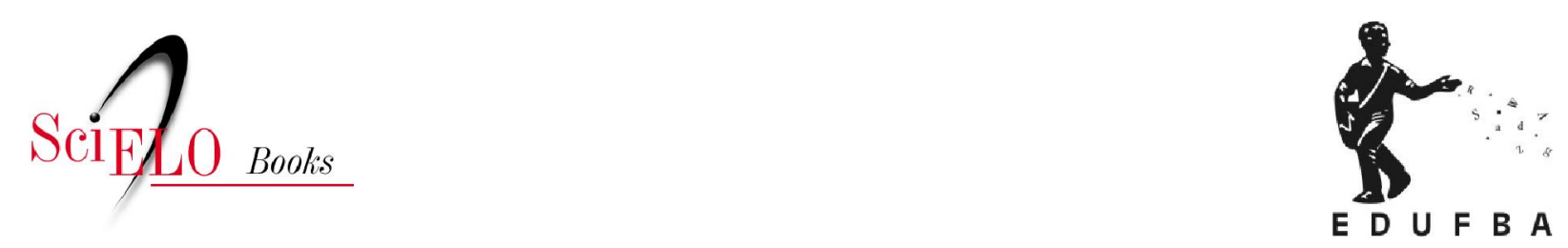

\title{
Movimento passe livre e as manifestações de 2013 A internet nas jornadas de junho
}

\author{
Maíra Ouríveis do Espírito Santo \\ Eduardo Henrique Diniz \\ Manuella Maia Ribeiro
}

\section{SciELO Books / SciELO Livros / SciELO Libros}

ESPÍRITO SANTO, M.O., DINIZ, E.H., and RIBEIRO, M.M. Movimento passe livre e as manifestações de 2013: a internet nas jornadas de junho. In: PINHO, J.A.G., ed. Artefatos digitais para mobilização da sociedade civil: perspectivas para avanço da democracia [online]. Salvador: EDUFBA, 2016, pp. 141-167. ISBN: 978-85-232-1877-5. https://doi.org/10.7476/9788523218775.0008.

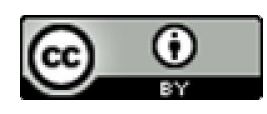

All the contents of this work, except where otherwise noted, is licensed under a Creative Commons Attribution $\underline{4.0 \text { International license. }}$

Todo o conteúdo deste trabalho, exceto quando houver ressalva, é publicado sob a licença Creative Commons Atribição 4.0.

Todo el contenido de esta obra, excepto donde se indique lo contrario, está bajo licencia de la licencia Creative Commons Reconocimento 4.0. 


\section{MOVIMENTO PASSE LIVRE E AS MANIFESTAÇÕES DE 2013 a internet nas Jornadas de Junho}

MAÍRA OURÍVEIS DO ESPÍRITO SANTO, EDUARDO HENRIQUE DINIZ, MANUELLA MAIA RIBEIRO

\section{INTRODUÇÃO}

Em junho de 2013, as ruas da cidade de São Paulo foram tomadas por milhares de pessoas como há muito não se via no país. Essas pessoas foram chamadas pelos atos do Movimento Passe Livre (MPL), que tem como uma das suas causas a adoção da tarifa zero no transporte público do país. Os atos tinham como objetivo protestar contra o aumento das tarifas no transporte público no município de São Paulo, que iam passar de três reais para três reais e vinte centavos.

No contexto dessas manifestações, que ficaram conhecidas como Jornadas de Junho, o uso da internet foi marcante. O MPL construiu um ciberespaço de discussão, de informação, de contrainformação e de divulgação de materiais que mostravam outras versões dos fatos, muitas vezes divergentes daqueles veiculados na grande mídia. A postura do MPL, favorável às novas mídias para construção de sua luta, é comprovada pela sua própria carta de princípios. Nela afirma que o movimento "deve utilizar mídias alternativas para a divulgação de ações e fomentar a criação e expansão destes meios. Já o contato com a mídia corporativa deve ser cauteloso, entendendo que estes meios 
estão diretamente atrelados às oligarquias do transporte e do Poder Público." (MOVIMENTO PASSE LIVRE, 2013a)

Frente às diversas possibilidades que a internet proporciona, a rede se constitui como um espaço de articulação de grupos, organizações e instituições. Os movimentos sociais incorporaram a internet para divulgar suas causas, lutas e estabelecer um diálogo direto com a sociedade sem depender dos grandes veículos de comunicação. A desconfiança em relação à mídia tradicional é reforçada por Caldas (2011), que aponta um novo tipo de coronelismo através do controle da mídia - elemento essencial na manutenção do poder das elites. Ainda mais porque, no Brasil, as emissoras de rádio e TV são concessões do governo e tendem a favorecer empresários e políticos que caminham lado a lado com o governo.

Os primeiros movimentos sociais que se apropriaram, de forma bem-sucedida, do ciberespaço utilizaram apenas lista de e-mails para apoiar suas atividades políticas. Em 1989, estudantes chineses ocuparam a Praça Tiananmen em protesto contra o regime e conseguiram, em grande medida, difundir o que se passava no país para a imprensa de todo o mundo, de forma totalmente independente da imprensa oficial. (CONKLIN, 2003) Em meados da década de 1990, foi o Exército Zapatista de Liberação Nacional (EZLN), do México (HILSENBECK FILHO, 2004; MORAES, 2000) que conseguiu compartilhar, de forma rápida, informações com muitos interlocutores acerca de como se encontrava a situação no país, quais eram seus propósitos e como fariam para alcançar seus objetivos.

Já nos anos 2000, alguns movimentos ganharam projeção internacional por terem conseguido mobilizar um grande número de pessoas, todos com um ponto em comum: a utilização das mídias eletrônicas descentralizadas como instrumento para articulação e divulgação de informações e materiais, como fotos, vídeos e textos. Castells e colaboradores (2005) relatam como o uso dos telefones celulares teve importante papel na organização de movimentos sociais nas Filipinas em 2001, na Coreia do Sul em 2002 e na Espanha em 2004. Mais recentemente, a série de manifestações conhecidas como Primavera 
Árabe, o movimento Occupy Wall Street e movimento dos Indignados, na Espanha, são os exemplos mais emblemáticos que acabaram por influenciar diversos movimentos de contestação em vários países.

No cenário brasileiro, o Movimento dos Trabalhadores Sem Terra (MST) faz uso do ciberativismo para se articular em rede, permitindo que seus militantes interajam com indivíduos dos mais diversos lugares do mundo, o que, consequentemente, propaga suas ideias de forma rápida e abrangente. (MILHOMENS, 2009) Entretanto, a maior expressão já vista no país do uso de mídias digitais na organização de ativismo social foram as Jornadas de Junho em 2013.

Assim, o objetivo deste artigo é identificar o papel da internet e da construção e compartilhamento de informações nas Jornadas de Junho, focando nas ações do MPL para convocar e divulgar as manifestações contra o aumento da tarifa do transporte público no primeiro semestre de 2013. Para compreendermos esse cenário e o lugar que a internet teve nesse processo, foram utilizadas referências bibliográficas relacionadas ao tema e também foi realizada entrevista com um dos integrantes da Comissão de Comunicação do MPL.

\section{O MOVIMENTO PASSE LIVRE}

Para compreendermos as Jornadas de Junho é necessário contextualizar o MPL, detalhando como o movimento foi fundado, quais as suas bandeiras e como está organizado. A exploração da história do MPL é relevante para a compreensão das Jornadas e permite enxergar como as mobilizações foram sendo gradativamente construídas. Parte-se da premissa de que as manifestações de Junho em São Paulo no ano de 2013 não foram um fenômeno isolado e descontextualizado.

Discussões sobre a gratuidade no transporte público ${ }^{\mathrm{I}}$ foram impulsionadas por alguns eventos que conseguiram avanços neste sentido.

I A proposta geral do movimento é que o serviço público de transporte seja pago por impostos progressivos para que assim seja abolida a tarifa. O movimento também propõe que a tarifa zero seja operacionalizada pela criação de um Fundo Municipal de Transporte Coletivo, gerido com a participação popular e mantido por arrecadação de multas de trânsito, estacionamento Zona Azul, parte do Imposto sobre a Propriedade de Veículos Automotivos 
Dignos de menção foram a Revolta do Buzu, ocorrida em 2003 em Salvador e a Revolta da Catraca, em Florianópolis no ano de 2004. (MANOLO, 2009) Durante o V Fórum Social Mundial, organizado por movimentos sociais de muitos países em Janeiro de 2005 em Porto Alegre, foi escrita e aprovada a Carta de Princípios que deu origem ao MPL. Se inicialmente limitava-se a defender o passe livre estudantil, o movimento ampliou a sua bandeira para defender o passe livre irrestrito, propondo a gratuidade do transporte público para todos os seus usuários. Em sua Carta, o MPL se propunha autônomo, horizontal, apartidário e independente. E desde o início, também adotou as mídias alternativas como instrumento de articulação e luta política.

Figura 1 - Logotipo do MPL

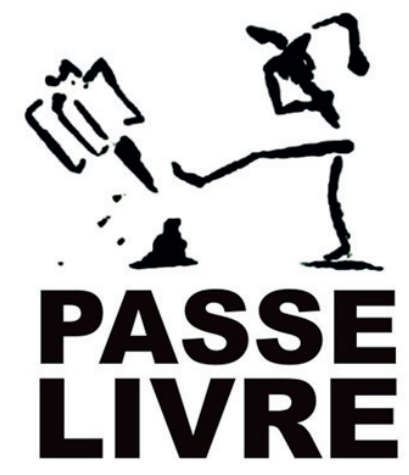

Com o lema "Por uma vida sem catracas", o MPL ressalta a catraca como um símbolo não apenas do transporte coletivo, mas também das desigualdades entre ricos e pobres, brancos e negros e homens e mulheres. O Movimento se compromete assim com o combate a "todas as catracas" que impeçam o acesso a espaços e serviços públicos.

(IPVA) e publicidade nos ônibus e terminais, nos metrôs e estações. (MOVIMENTO PASSE LIVRE, 2013b) O MPL também pretende estudar formas de tornar a participação popular efetiva, usando como modelo de sucesso os conselhos regionais de saúde existentes na cidade de São Paulo, formados por representantes da sociedade civil. 
Para o MPL, a gratuidade no transporte público é tratada como direito de todos já que

[...] $35 \%$ da população que vive nas cidades grandes não tem dinheiro para pagar ônibus regularmente. Inclusive, muitas pessoas estão excluídas de acesso a outros direitos e serviços públicos, como os relacionados à educação, porque não podem pagar o ônibus até a escola. (MOVIMENTO PASSE LIVRE, 2013b)

Para atingir seus objetivos, o MPL faz uso de diversas táticas, como ocupação de terminais de ônibus, fechamento de vias de circulação de automóveis, entrar pela porta traseira do ônibus ou descer pela da frente, passar por baixo da catraca do ônibus ou pular as catracas dos terminais ou estações (conhecido também como "catracaço"). (MOVIMENTO PASSE LIVRE, 2013c) No município de São Paulo, o Movimento contesta o sistema de transporte municipal desde 2006. Contudo, foi em 2013 que as manifestações encabeçadas pelo MPL contra o aumento da tarifa do transporte público em São Paulo tomaram grandes proporções e ganharam força para influenciar outros protestos pelo país inteiro.

\section{AS JORNADAS DE JUNHO}

As manifestações na capital paulista conhecidas como Jornadas de Junho foram desencadeadas pelo reajuste da tarifa do transporte público de três reais para três reais e vinte centavos no final de maio. Sete atos contra o aumento foram convocados pelo MPL na cidade de São Paulo, porém estima-se que 1,5 milhão de pessoas em mais de 120 cidades no Brasil saíram às ruas como resultado destas manifestações. (FERNANDES; ROSENO, 2013) Tal fervor das ruas não se verificava há pelo menos duas décadas: as últimas grandes manifestações no país haviam sido as do Fora Collor, em 1992, e antes disso as Diretas Já, entre 1983 e 1984. (SIMEONI, 2013)

Os protestos chamados pelo MPL naquele ano partiram inicialmente da organização de estudantes secundaristas, como os da Escola 
Estadual Ermano Marchetti, em Pirituba, bairro do noroeste da capital. Neste primeiro ato, aproximadamente 200 estudantes ocuparam o terminal de ônibus e a estação de trens da Companhia Paulista de Trens Metropolitanos (CPTM) de Pirituba, queimaram uma catraca e bloquearam ruas e avenidas de grande circulação da região. (MOVIMENTO PASSE LIVRE, 2013a) Outros atos regionais em outras escolas se seguiram e precederam os enormes protestos que levariam uma quantidade enorme de pessoas às ruas em torno de outras bandeiras que foram levantadas no decorrer das manifestações. Cabe destacar que o momento em que os grandes atos aconteceram em São Paulo e, posteriormente, no país todo, era um momento especial para o Brasil: em diversas cidades brasileiras, aconteceu, de 15 a 30 de junho, a Copa das Confederações FIFA 2013, com os olhos da mídia internacional voltados para o país.

O assim chamado " $1{ }^{\circ}$ Grande Ato" foi marcado para o dia 6 de junho e contou com a participação de cerca de 2 mil pessoas. Os manifestantes fecharam as Avenidas 9 de Julho, 23 de Maio e também a Avenida Paulista. A Polícia Militar, para dispersar os manifestantes, fez uso de bombas de gás lacrimogêneo e de efeito moral (FERNANDES; ROSENO, 2013), os manifestantes, por sua vez, tentaram dificultar a aproximação da polícia fazendo barricadas com cones, sacos de lixo e fogo. Também ônibus e prédios foram pichados. Ao final, 50 pessoas ficaram feridas e 15 foram presas. (PIRES, 2013) Tanto o governador do Estado, Geraldo Alckmin, quanto o prefeito Fernando Haddad alegavam, a esta altura, ser impossível atender à pauta do MPL. (FERNANDES; ROSENO, 2013)

Paralelamente, entretanto, o tema começa a ser divulgado também em sites ligados à questão da mobilidade urbana. Contrariando as declarações oficiais do poder público que dizia que o reajuste das passagens seguia abaixo do valor da inflação, foi divulgado que, pelo cálculo do IPCA² (IBGE) a tarifa do ônibus que era de R\$o,50 em 1994 deveria

2 De acordo com o Portal Brasil, a sigla IPCA significa Índice Nacional de Preços ao Consumidor Amplo e é o índice oficial do governo federal para metas inflacionárias, calculado pelo Instituto Brasileiro de Geografia e Estatística (IBGE). 
ser de R\$ 2,16 em 2013, e o metrô R\$ 2,59, considerando o índice de inflação de 332,22\% nesses 19 anos. Ou seja, o valor deveria, sim, estar abaixo dos R\$3,20. (EVOLUÇÃO..., 2013) A viabilidade da pauta do MPL também se mostrava realista pelo fato de já ter sido discutido na cidade o Projeto Tarifa Zero, de Lúcio Gregori, na época em que era secretário municipal de transportes da gestão da prefeita Luiza Erundina (1989-1992). (ALLEGRINI, 2013) Mesmo tendo sido arquivado, o projeto era um antecedente importante na cidade, dentro da própria Câmara de Vereadores, e mais pessoas deixavam de ver a pauta como utópica.

$\mathrm{O} 2^{\circ}$ Grande Ato contra o aumento das passagens de ônibus, metrô e trem foi então marcado para o dia seguinte, 7 de junho de 2013 . Dessa vez, cinco mil manifestantes aderiram ao evento e bloquearam a Marginal Pinheiros no sentido Castelo Branco, no horário de 19 h15 as 19h45. (PIRES, 2013) Para desmobilizar os participantes do protesto e fazer com que o trânsito fosse rapidamente liberado, a PM fez uso das bombas de gás lacrimogêneo, de efeito moral bem como spray de pimenta e balas de borracha. (FERNANDES; ROSENO, 2013)

Nesse momento, surgem os militantes Black Bloc que respondem à ação da polícia. De acordo com Judensnaider (2013), a origem dos Black Blocs remete ao movimento autonomista da Alemanha nos anos 1980, com manifestantes mascarados e vestidos de negro (der schwarze Block ou "o bloco negro") para dificultar a identificação da polícia. O "bloco negro" no seu modelo alemão se propunha a oferecer proteção às passeatas, limitando a infiltração de agentes provocadores e defendendo os manifestantes dos ataques da polícia.

Os Black Blocs reaparecem nos Estados Unidos, uma década mais tarde, nos protestos contra a Organização Mundial do Comércio (OMC) em Seattle, dessa vez orientados à destruição de propriedade privada como forma de protesto. Essa nova postura do grupo gera muita controvérsia entre os ativistas alinhados com a estratégia de não violência.

Embora a imagem do Black Bloc americano prevaleça no imaginário brasileiro (a começar pelo nome em inglês), na manifestação do dia 7, os Black Blocs assumem uma postura "clássica", articulando 
suas ações com a estratégia geral do MPL e se esforçando para proteger os manifestantes, ao invés de expô-los a mais violência.

Outro grupo, o Anonymous, também entra em cena ao invadir o site da Secretaria Municipal de Educação de São Paulo, deixando um chamado para o próximo ato. (JUDENSNAIDER, 2013) O Anonymous ficou internacionalmente conhecido em 2008 quando declarou guerra contra a cientologia. A partir de 2011 o grupo ganhou um caráter politizado, tendo tido forte participação no movimento Occupy, na Primavera Árabe e na luta pela liberdade na internet. Atuam hackeando sistemas de um alvo definido, em geral sites de bancos, governos, órgãos internacionais e de agências de controle de cartões de crédito. Além disso, hackeam bases de dados e disponibilizam para o público vídeos e dados pessoais de políticos. (GOHN, 2013) Por serem parte de um grupo internacional, assim como os Black Blocs, o Anonymous ajudou a mostrar as manifestações de Junho para o mundo.

Em 11 de junho, 12 mil pessoas aderiram ao $3^{\circ}$ ato, que teve início na Avenida Paulista, passou pelo centro e voltou para a mesma avenida, contabilizando, assim, seis horas de caminhada dos manifestantes. Na região da Praça da Sé, foram feitas pichações em prédios, e alguns chegaram a ser depredados, ônibus foram atacados na região do Parque D. Pedro II. (PIRES, 2013) A Polícia Militar, com a ordem de não permitir a entrada dos manifestantes no Parque, fez uso dos mesmos recursos usados nas manifestações anteriores. (FERNANDES; ROSENO, 2013)

Com um novo ato convocado para o final do dia 13 de junho, o jornal Folha de São Paulo publica um editorial com o título "Retomar a Paulista” em que classificava o MPL como um grupelho de bandeira irrealista. Neste editorial, propõe que "É hora de pôr um ponto final nisso. Prefeitura e Polícia Militar precisam fazer valer as restrições já existentes para protestos na Avenida Paulista, em cujas imediações estão sete grandes hospitais." (RETOMAR..., 2013, p. A2) O jornal O Estado de São Paulo também publica, na sessão Opinião, um artigo com o título "Hora do basta", condenando as manifestações. Tais posturas, aparentemente, "deram o sinal verde" para o aumento da intensidade da repressão policial que se seguiu naquela noite e que pode ser con- 
siderado divisor de água das Jornadas. $\mathrm{O} 4^{\circ}$ ato, de 13 de junho, com aproximadamente 10 mil pessoas na rua (COLETIVO DE REGISTRO DA LUTA CONTRA O AUMENTO, 2013) ganhou relevância dentro dessa série de manifestações pela intensidade da repressão policial. Antes mesmo de o protesto ter início, cerca de 40 pessoas foram presas na concentração. Conforme a manifestação foi recebendo mais participantes durante seu desenrolar e se encaminhando para parar o tráfego na Avenida Paulista, a Polícia Militar obtinha ordens de não permitir que os manifestantes chegassem ao seu destino. Sendo assim, 400 homens da polícia deram início à repressão de maneira indiscriminada, com o uso de gás lacrimogêneo, spray de pimenta e balas de borracha. A Tropa de Choque da Polícia Militar atirava mesmo sob gritos de não violência. "Pessoas que sequer participavam do protesto, mas estavam nos arredores, em lojas e bares, também sofriam agressões por parte dos policiais". (FERNANDES; ROSENO, 2013, p. 19) cento e trinta pessoas foram detidas, e cento e cinco ficaram feridas.

Um aspecto em especial da atuação da polícia fez com que a repressão fosse tão repudiada: muitos repórteres da grande mídia, mesmo que identificados com crachás, foram agredidos. O repórter Piero Locatelli, da revista Carta Capital, foi detido violentamente por "porte de vinagre", 3 pois esta substância é utilizada pelos manifestantes para amenizar os efeitos do gás lacrimogêneo. O fotógrafo do Portal Terra, Fernando Borges, também foi detido e ficou 40 minutos de frente para a parede, junto com outros manifestantes (MAGALHÃES; NOVAES, 2013) e a repórter Giuliana Vallone, da Folha de São Paulo, foi atingida por uma bala de borracha no olho. (PIRES, 2013)

A revolta em relação à atuação policial aumentou conforme fotos, relatos e vídeos postados nas redes sociais por pessoas que saíam do cenário de guerra em que se tornou a região da Rua da Consolação. A grande mídia, que no dia anterior deslegitimara os atos apontando os manifestantes como baderneiros e rebeldes sem causa, revisou suas impressões iniciais sobre os protestos e participantes. Não havia como

3 As manifestações ganharam o apelido de Revolta do Vinagre devido às diversas detenções de pessoas por porte de vinagre. 
questionar vídeos com policiais destruindo uma viatura da corporação para culpar manifestante, ou atirando com balas de borracha dentro de apartamentos de pessoas com câmeras, ou ainda utilizando fardas sem os nomes na lapela. As hashtags ${ }^{4}$ \#vemprarua e \#OGiganteAcordou começaram a se tornar cada dia mais comuns nas redes sociais, com o intuito de chamar mais pessoas a participarem das manifestações e saberem a realidade das ruas.

O volume de materiais compartilhados na internet fazia com que os usuários das redes sociais percebessem “[...] que estavam com dois enormes poderes nas mãos: produzir e distribuir informações”. (FERNANDES; ROSENO, 2013, p. 53) Isso lhes dava a consciência de que podiam fazer uso das redes sociais para informar o público em geral, de forma mais ampla e isenta, do que a mídia tradicional vinha até então fazendo.

É quando o grupo Mídia Ninja, ligado ao coletivo da área cultural Fora do Eixo, ganha destaque nas Jornadas de Junho. O grupo - Ninja significa Narrativas Independentes, Jornalismo e Ação - transmitia as manifestações pelo país em tempo real, com câmeras de celulares ligados ao site Pós-TV, recheando as imagens com debates e discussões. A proposta era apresentar uma forma diferente de televisão, permitindo a interação dos espectadores com os produtores do programa, principalmente via comentários no próprio site durante o acontecimento.

O Mídia Ninja, com uma narrativa alternativa àquela da mídia tradicional, mostrava que havia outro lado da história, buscando desconstruir o discurso de que a polícia somente havia tomado atitudes extremas por que havia sido atacada primeiro. Com isso, desmascarava a grande mídia que havia tentado desmobilizar os manifestantes e deslegitimar a causa. A rejeição às grandes redes de televisão se tornou tão evidente que os repórteres passaram a ter que retirar o logo da emisso-

4 Hashtags são as palavras precedidas pelo sinal \# que viram hiperlinks nas redes sociais, para apontar os assuntos dos quais se está falando. Ao adicionar o \# a alguma palavra e publicá-la, o usuário permite que quem esteja lendo e clicar nela veja todas as outras pessoas que também publicaram tal palavra desta mesma maneira. Este recurso, permite contabilizar a quantidade de menções feitas a determinado assunto, e assim avaliar a relevância de determinada discussão nas redes sociais. 
ra de seus microfones quando iriam fazer transmissões em meio aos manifestantes.

Os próprios meios de comunicação em massa começam então a mudar sua abordagem dos atos e passam a revelar a repressão policial. A Polícia Militar paulistana é rotineiramente truculenta e excessiva para os movimentos sociais na periferia, contudo esses abusos não causavam tanta comoção. Os alvos, desta vez, eram brancos de classe média e os repórteres e fotógrafos das grandes agências. (ALLEGRINI, 2013; SECCO, 2013)

No dia seguinte, as ações policiais foram duramente criticadas pela população, pelo governo e pela imprensa nacional e internacional. Os registros das agressões estampavam as capas de revistas e jornais mais importantes do Brasil e do mundo. [...] A posição dos veículos de comunicação mais conservadores se alterou, e duras críticas foram feitas às ações violentas e ao despreparo da polícia que reagiu contra os manifestantes. (FERNANDES; ROSENO, 2013, p. 19)

A partir daí, os atos ganhariam outra forma e outro sentido, já que as manifestações se disseminaram por todo o país Brasil. Com o aumento da lista de cidades organizando protestos, aumentava também a diversidade das reivindicações. (JUDENSNAIDER, 2013) A mídia que antes mencionava os atos apenas durante os noticiários de sua grade de programação, passou a cobri-los em tempo real, com repórteres ao vivo, direto dos locais das manifestações. A mobilização começa a ser relatada pela sua abrangência nacional, e não apenas como protestos isolados. Contudo, os meios de comunicação retratavam o movimento como composto por dois grupos: um com pessoas bem-intencionadas e outro com vândalos responsáveis pela degradação e má fama dos atos.

Ao longo do final de semana, entre o ato do dia 13 e o seguinte, marcado para o dia 17 , as postagens nas redes sociais ganharam uma nova característica interessante. Tanto em perfis de pessoas quanto de coletivos e organizações, apareciam orientações sobre como agir durante a manifestação, indicando, por exemplo, o uso de vinagre para 
aliviar os efeitos das bombas de gás lacrimogênio lançadas pela polícia e as saídas para evitar a revista da Polícia Militar em busca de vinagre.

Após o ato do dia 13, passaram a ser comuns postagens sobre como ajudar o movimento sem necessariamente ir às ruas, pois o medo havia tomado conta de muitos depois das violentas imagens da manifestação anterior. Algumas sugeriam desde abrir as redes wifi para facilitar a troca de informações ou colocar lençóis brancos nas janelas em apoio aos manifestantes, até lugares em que haveria postos de atendimento médico. (JUDENSNAIDER, 2013, p. 136) Uma rede de apoio foi sendo construída ainda que não necessariamente em torno da pauta dos $\mathrm{R} \$ 0,20$.

Numa clara indicação da mudança da orientação editorial, no dia 15 de junho o jornal $O$ Estado de São Paulo publica um artigo na seção Opinião intitulado "Entender as manifestações", com uma postura muito mais branda do que aquela do dia 13. A Folha de São Paulo reconhecia a violência da Polícia Militar no editorial publicado com o título "Agentes do caos":

A Polícia Militar do Estado de São Paulo protagonizou, na noite de anteontem, um espetáculo de despreparo, truculência e falta de controle ainda mais grave que o vandalismo e a violência dos manifestantes, que tinha por missão coibir. Cabe à PM impor a ordem, e não contribuir para a desordem. (ENTENDER..., 2013, p. A2)

Em 17 de junho, 65 mil pessoas (ATO..., 2013), participaram do $5^{\circ}$ Ato chamado pelo MPL. A concentração se deu no Largo da Batata e se dividiu em três frentes. Uma cruzou os Jardins até a Avenida Paulista. Outra passou pela Ponte Eusébio Matoso e pela Marginal Pinheiros, seguindo até a Ponte Octavio Frias de Oliveira (Ponte Estaiada), sobre o Rio Pinheiros. E a última passou pela Avenida Brigadeiro Faria Lima, pelo Itaim-Bibi e também se dirigiu à Ponte Estaiada. De lá se juntaram ao grupo que havia se dirigido à Av. Paulista, e uma parte se desviou para a Avenida 23 de maio. (PIRES, 2013) Ao passar pelas principais vias de fluxo de automóveis da capital paulista, a manifestação obteve demonstrações claras de apoio da população, com pessoas jogando pa- 
pel picado ou estendendo panos brancos nas janelas. Em contraste com a manifestação anterior, neste dia não houve repressão.

Na Avenida Faria Lima, apenas seis policiais acompanhavam o protesto. (BRITO; BREDA, 2013) Bombas de gás e balas de borracha não foram usadas. Durante a caminhada, gritos de "que coincidência, não tem polícia, não tem violência”, deixavam clara a percepção de que os confrontos tinham origem no uso abusivo da força policial.

Em contradição com as declarações dadas ainda durante as primeiras manifestações, em 19 de junho, o governador Alckmin e o prefeito Haddad anunciam a revogação do reajuste da passagem do transporte público em São Paulo, que voltou a custar R \$3,00. (JUDENSNAIDER, 2013) Indubitavelmente, uma vitória, e que precisava ser comemorada nas ruas.

Novo ato chamado pelo MPL para 20 de junho contou com cerca de 110 mil participantes. (EM DIA..., 2013) O MPL reconhecia que, apesar de ter alcançado o que era objetivo do momento, precisava continuar fiel a sua pauta de tarifa zero. A manifestação comemorativa indicaria, portanto, apenas que parte de um longo caminho havia sido trilhado para que essa luta fosse de fato vencida.

Em todo o país, mais de cem cidades conseguiram a revogação do aumento da tarifa de transporte público. O povo continuou e continua nas ruas por diversas outras pautas. Por outro lado, a descrição das manifestações ocorridas em junho de 2013 na cidade de São Paulo chamam a atenção para a necessidade de aprofundamento do olhar sobre o assunto. Até o momento, tem-se a narrativa dos acontecimentos, mas não exatamente a compreensão completa do cenário que propiciou o advento das Jornadas de Junho.

\section{AS JORNADAS DE JUNHO E A INTERNET}

A internet, como mencionado em trechos da descrição aqui feita, foi importante para fazer circular informação, construir versões alternativas dos fatos àquelas propostas pela mídia em geral. Por mais que muito se discuta sobre o papel da rede para os movimentos sociais, os fatos recentes no Brasil e no cenário mundial mostram que existe uma 
contribuição importante da internet para a comunicação alternativa e a articulação desses movimentos. A contraposição entre mídia tradicional e mídia alternativa ressalta essa oportunidade criada pela rede.

Mesmo para aqueles de menor poder econômico, a internet aparece como um meio alternativo de comunicação, pois hoje nas favelas brasileiras 50\% dos domicílios já possui acesso à rede. (PAPP, 2013) Apesar da televisão e o rádio constarem ainda como os principais meios de comunicação, a internet apresenta um grande potencial a ser explorado.

Acontecimentos recentes relatados neste capítulo evidenciam como a internet se constituiu num meio para divulgação de versões diferentes àquelas transmitidas pela grande mídia, tornando possível o acesso às informações que não estavam pautadas pela TV, rádio e jornais e revistas tradicionais. A divulgação de vídeos, áudios e imagens também permitiram a comprovação da veracidade das versões alternativas:

Curiosamente, foram as redes sociais que permitiram isso. Vejam o que aconteceu na Tunísia ou no Egito, onde ditaduras muito antigas, de mais de cinquenta anos, acreditavam que já dominavam a sociedade porque controlavam o rádio, a televisão e a imprensa escrita. Mas, de repente, as novas gerações começaram a conhecer o conteúdo do WikiLeaks, repassando a informação pelo Facebook, Twitter ou e-mail. Elas se autoinformaram, protestaram, criaram uma contraopinião pública, e as ditaduras não puderam resistir. Atualmente, os jovens do mundo - na Espanha, nos Estados Unidos, na Grécia, na Inglaterra, em Israel, no Chile - estão se autoinformando e protestando contra uma espécie de aliança entre os poderes tradicionais e o poder midiático. (RAMONET, 2013, p. 99)

Os movimentos sociais recebem, em geral, cobertura parcial e desfavorável da mídia. Neste aspecto, são oprimidos não apenas em suas manifestações de rua, mas também ao serem retratados de forma negativa pelos principais agentes de formação da opinião pública:

[...] os grupos dominantes, associados com militares e policiais, continuam a criminalizar amplos setores da sociedade civil, principalmente as manifestações mais firmes de traba- 
lhadores da cidade e do campo. Auxiliados por uma parte dos meios de comunicação de massa e da indústria cultural, insistem em desqualificar e reprimir as reivindicações populares. Classificam as mais óbvias manifestações da questão social como problemas de 'violência' urbana e rural. Afirmam cotidianamente que a violência é a do outro. (IANNI, 1989 apud CALDAS, 2011, p. 34)

O comportamento da mídia tradicional durante as Jornadas de Junho é revelador. Enquanto os jornais de grande circulação chamavam os manifestantes de vândalos, na internet circulavam vídeos de policiais depredando os próprios carros e atirando dentro de residências. Ao adotar uma via alternativa de comunicação com a sociedade, os movimentos sociais conseguem mostrar a sua versão dos fatos, independente do filtro da mídia, influenciando diretamente a opinião pública e, em alguns casos, como foi visto aqui, a própria mídia tradicional. Nesse contexto:

A utilização da Internet, de redes eletrônicas de comunicação e o volume de informações produzidas e transmitidas, são também responsáveis pelo escape à tradicional (e muitas vezes velada) censura dos meios de comunicação, favorecendo o elemento surpresa e a escolha do momento para sua ação política, como a data definida para o início do conflito, que conseguiu a atenção da mídia, repercussão e reconhecimento da guerrilha como ator político que não poderia mais tão facilmente ser silenciado pelo governo e os meios de comunicação oficiais. (HILSENBECK FILHO, 2004, p. 2)

Entretanto, se a tecnologia pode ser mais um instrumento na articulação das lutas sociais, ela não deveria ser encarada como o elemento principal que dá vida aos movimentos que levam as bandeiras dessas lutas. É preciso encontrar um meio termo entre a aversão à tecnologia e o seu endeusamento.

De qualquer forma, as novas tecnologias da internet precisam ser incorporadas pelos movimentos sociais. Como citado no início deste capítulo, elas ajudam a ampliar a capacidade desses movimentos, per- 
mitindo a troca de informação de forma descentralizada, o que faz com que qualquer pessoa possa ser um agente de divulgação, em oposição à estrutura rígida de veiculação de informações da mídia tradicional.

Os blogs possibilitaram que alguém com pouco conhecimento sobre os sistemas jornalísticos publicasse seus textos e imagens para qualquer pessoa que quisesse acessá-lo. Indo além, as redes sociais facilitaram a propagação de informações em tempo real, acelerando a circulação de conhecimento sobre algum fato ou fenômeno que, em geral, não atrairia um jornal estabelecido e nem teria tempo para ser encaminhado através de uma redação tradicional. A portabilidade dos dispositivos celulares potencializou ainda mais essa troca de informações, permitindo com que as pessoas divulguem o que desejam, em tempo real, do local do acontecimento.

\section{A INTERNET E O MOVIMENTO PASSE LIVRE}

Dados do Comitê Gestor da Internet no Brasil (2014) mostram que $85 \%$ da população brasileira usou o telefone celular nos últimos três meses. Destes, 31\% usou a internet no celular. Entre os que utilizaram internet no celular, $73 \%$ o fizeram diariamente, $20 \%$ uma vez por semana, $5 \%$ uma vez por mês e $2 \%$ menos de uma vez por mês. Esses fatores levam à vivência de uma nova experiência de tempo e espaço. (HARVEY, 2006) Todas essas tecnologias, em especial as redes sociais, fizeram com que as Jornadas ganhassem tamanha dimensão. Ao dar voz ao próprio MPL, é possível colher as impressões desta organização sobre o papel da internet no processo de construção e articulação das lutas sociais. Como relatou em entrevista ${ }^{5}$ um dos responsáveis pela comunicação do MPL:

[...] os próprios manifestantes noticiando, no Facebook, tirando foto, colocando vídeo no Youtube, noticiando pras pessoas, falando 'tirei a foto aqui, olha a bala de borracha que eu tomei', 'olha esse cara, como é que ele tá', 'tô aqui na delegacia há 'x' horas'

5 Entrevista realizada como parte da pesquisa empírica da dissertação de Espírito Santo (20I4), Lutas sociais e ciberespaço: o uso da internet pelo Movimento Passe Livre nas manifestações de junho de 2013 em São Paulo. 
Eles têm um papel muito importante na informação, quanto mais gente falando... A gente acha que grande parte do tamanho que toma é porque a maioria das pessoas se apropriaram disso e elas se tornam sujeitos também da luta, quanto mais gente lutando melhor. O MPL não é a única organização que tá nessa luta e nem quer ser. Gente que tá lutando pelo transporte e não tá no MPL, maravilha. Gente que tá na manifestação e tá fazendo a notícia, não precisa ser uma página oficial do Facebook, do MPL, do Passe Livre São Paulo pra ter uma relevância na importância da luta, é isso. Teve uma importância muito grande em desmistificar e deslegitimar uma versão que estava sendo mantida pela mídia [...]. (MILITANTE MPL, 2013)

Da maneira geral, o MPL tem claro que precisa se organizar para trabalhar a sua comunicação, elemento bastante relevante da própria ação que cabe aos movimentos sociais. A existência de uma Comissão de Comunicação estruturada dentro do movimento mostra a importância desse aspecto para o MPL:

A gente busca ser dono da própria luta, a nossa comunicação é feita por nós mesmos, a gente não vai esperar que a Globo faça a cobertura do nosso ato, isso nacionalmente, e a gente não vai esperar que a divulgação do nosso ato saia na Folha de São Paulo, então como que a gente faz, das mais diversas maneiras, das mais diversas táticas, a gente faz essa divulgação, e ai vale o quê? Vale internet? Vale. Vale evento no Facebook? Vale, mas a gente existia antes do Facebook existir. Vale comunidade no Orkut? Vale, mas tudo isso ai vem antes das coisas tomarem uma proporção muito grande no Brasil, então isso vem de antes, vai do boca-a-boca, de eventos, de discussões, de debates, vai de panfletagens, de colagem de lambes, de cartazes, tem as mais diversas maneiras para que a gente consiga, que a gente possa, porque a gente tem a questão financeira. O financeiro é muito forte, boa parte da nossa estética ela é em preto e branco hoje em dia porque a gente não tem dinheiro pra rodar panfleto colorido, a gente não tem tempo pra fazer mil atos, então a gente faz isso porque é o que dá. A gente busca ser dono da própria comunicação, a gente tem a nossa página nos meios, a gente tem o nosso site, é lá que a gente informa 
a nossa versão, porque não é confiável, a gente entende que tem uma disputa política e nessa disputa política tem gente que se utiliza dos mais diversos meios pra fortalecer seu lado, então é isso, a manifestação é sobre transporte, boa parte das pessoas que estão lá sabe que é pro transporte, tá lá pelo transporte, mas mesmo assim vai sair outra coisa no jornal. Mesmo assim vai sair outra versão. (MILITANTE MPL, 2013)

Dentro do universo de possibilidades da internet, o MPL enxerga a grande relevância da comunicação, mas é interessante perceber que também enxerga as limitações da rede na construção de suas lutas e reconhece as incontáveis potencialidades de ação da internet, mas não crê que ela venha a resolver todos os problemas:

O Facebook ele tem uma força muito grande em alguns aspectos, em outros aspectos o Youtube tem uma função muito importante pra sinalizar as agressões policiais. O CMI [Centro de Mídia Independente] tem essa função histórica de servir como agregador dessas mídias, dos blogs e tudo mais. Tumblr agora teve para mostrar as fotos. Eles têm essa importância sim, das pessoas mostrarem, terem acesso a essa possibilidade, mas assim duvido que... Se não tivesse Internet ainda ia ter Junho, se não tivesse o evento no Facebook para convidar os amigos, iriam mandar mensagens de celular pra eles, ou ia chegar no trabalho e falar pra eles, se não tivesse Tumblr pra mostrar as fotinhos, você ia chegar lá, arregaçar a calça da perna e mostrar a porra da bala de borracha, ou você ia chegar no trabalho e o cara ia ver sua cara, o jeito que ela tava. É isso, tem sua importância, mas tem seus limites e contextualizar isso, abre um caminho pra uma coisa muito complicada, como se não fosse uma questão das pessoas lutando, como se as mídias fossem os instrumentos mobilizatórios, não é isso, tá longe disso. (MILITANTE MPL, 2013)

Na fala do militante do MPL, aparecem várias redes e mostra que o MPL tem consciência da possibilidade de ação e divulgação de informações em diversas frentes e em diferentes formatos. Ao discorrer sobre outras formas de uso do ambiente virtual, o representante do MPL também demonstrou a existência de articulação com outros gru- 
pos que também buscam mudanças. Ratifica que vida real e virtual não somente se complementam, mas se sobrepõem e as lutas devem se dar em ambos os ambientes.

A gente tem tentado usar agora mais livestreaming com ajuda de outros coletivos de mídia alternativa, de mídia independente que tem esse debate já feito. CMI, Passa-Palavra, Ação Direta de Vídeo Popular, Mídia Negra são muitos coletivos que apoiam a gente nisso. (MILITANTE MPL, 2013)

Tal articulação fortifica a luta dos movimentos sociais e amplia suas discussões. Contudo, apenas a publicação na rede não pode limitar a ação nem de indivíduos nem dos movimentos. Se há possibilidade de responder às publicações feitas nos perfis do MPL nas redes sociais permite criar interação com outros indivíduos interessados na mesma luta, Luca alega que a atual composição do MPL não favorece a manutenção desta dinâmica.

Isso não significa que o MPL apenas faz divulgação na rede e não acompanha o que acontece depois. Luca explica que, embora o monitoramento da página do MPL no Facebook, por exemplo, seja superficial, se há muitos compartilhamentos, pode-se entender que as pessoas compreenderam o que fui publicado. Partindo da interpretação da resposta das pessoas, o MPL busca elementos para planejar como continuar construindo sua comunicação direta.

Essa preocupação do MPL em se fazer entender e em estabelecer um diálogo demonstra uma consciência de seu poder de conscientização, informação e até de educação. Ao demonstrar disposição em se fazer entender e não estar fechado em si mesmo, o MPL se considera de fato comprometido em levar sua luta a outros patamares de discussão e atuação. Talvez este tenha sido um dos fatores que ajudou na popularização do MPL na rede. Luca diz que, antes das Jornadas de Junho a página Passe Livre São Paulo no Facebook tinha 10 mil curtidas. Este número saltou para 295 mil durante as Jornadas. Contudo:

[...] no pico da luta contra o aumento, no final dela, dia 19, a gente tinha, aproximadamente, 8 a 10 milhões, teve um crescimento 
muito grande. [...] É um negócio que atinge uma proporção meio irreal também, não são 295 mil pessoas que são do Passe Livre, nem que adoram o Passe Livre, nem nada, são 295 mil pessoas que curtem a página, é isso. É tudo isso que significa. E isso aí tem todas as problemáticas, não são essas pessoas que acham importante fazer a discussão dos transportes, são pessoas que curtem a página, a gente tem noção disso, é muito importante ter essa noção. (MILITANTE MPL, 2013)

Novamente está presente a ponderação entre possibilidades e limites do uso da rede. Isto é de extrema relevância para não alardear o entusiasmo com a tecnologia sem refletir sobre seus limites e oportunidades para os movimentos sociais. Ao mesmo tempo, não se deve diminuir a importância que a internet pode vir a ter para os movimentos sociais. Fazer ouvir/ler as ruas na rede é uma luta política paralela contra a mídia tradicional. E uma luta com obstáculos muito maiores se for levado em conta o cenário de um país com a extensão e as características socioeconômicas como o Brasil. Há uma grande diversidade de mundos dentro do próprio território nacional. "Dialetos" regionais, parcas condições de infraestrutura, realidades muito opostas dentro de um mesmo ambiente. Quanto ao uso da internet nessa realidade, o MPL considera que:

[...] Você atinge só uma parte da população, talvez seja importante pra essa parte da população, seja uma boa estratégia para atingir essa parte da população. Porque agora tem um pouco mais de crescimento econômico de umas certas camadas, da popularização de acesso à Internet, então você diminui assim, mas é aquela velha história, aquele velho mito... um dia fizeram uma pesquisa de apoio eleitoral nos Estados Unidos entre 2 presidentes, só que fizeram-na pelo telefone só que só tinha acesso ao telefone quem era rico, então o resultado foi o outro, o resultado da eleição no mundo real foi completamente distinto. Então a gente tem essa noção, a gente pode ter 20 milhões de curtidas, mas no fundo o que importa mesmo não é Internet. A Internet faz parte da vida, mas o que importa é o mundo concreto, o que importa é a gente fazer atividade no terminal. Onde estão as pessoas que usam ônibus: 
mais na Internet ou mais no terminal de ônibus? A gente sempre tem que pensar pra atingir. Será que é mais proveitoso a gente fazer na Internet ou a gente fazer uma panfletagem? A gente, muitas vezes, acha mais vantajoso fazer a panfletagem. Internet é muito esse domínio do espetáculo, de um mundo muito irreal, muito inatingível, muito limitado, considerando as dimensões do país, de São Paulo e o contexto socioeconômico será que vale a pena se pautar pela internet? Será que vale a pena se pautar pelo espetáculo? A gente acha que não. Acha que vale mais a pena se pautar pelo mundo concreto, pelo mundo que não tá aparecendo nas notificações do dia a dia, pelo mundo que não vai ser compartilhado 20 milhões de vezes no Facebook, e sim pelo mundo que as pessoas enfrentam todo dia, pelo passinho pra trás que as pessoas tem que dar, todo dia, pra caber nos ônibus, pelo sufoco, pelas cotoveladas, pelos apertos que elas tem que dar no trem pra entrar nele. A gente prefere se pautar por isso do que por questões tão espetaculares. [...]. (MILITANTE MPL, 2013)

Para o MPL, dentro das próprias Jornadas pode ser vista uma diferença entre as características do seu período inicial e de seu fim:

Acho que tem dois momentos. Aliás, acho que tem vários momentos na luta contra o aumento de 2013, momentos particulares. Tem uma posição da mídia, muito clara, até o dia 13, incluindo o dia 13, incluindo a edição da manhã do dia 13, então você tem esse primeiro momento. Nesse primeiro momento você tem o Primeiro Ato, que era muito grande, do tamanho de um dos maiores atos desde 2011 que foi a última luta contra o aumento, então você já tem uma maior informação, já tem uma maior legitimidade de lutar, de desnaturalizar o aumento da passagem e de desnaturalizar o transporte como mercadoria, você tem essa luta como legítima, o pessoal tá falando assim: 'O transporte tem que ser direito, é minha cidade, é meu transporte, eu deveria poder usar do jeito que eu bem entender e decidir sobre ele', então, você tem, cada vez mais, as pessoas tendo essa posição, acho que isso é um processo histórico e talvez o MPL tenha alguma parte nisso, eu acho que tem, algo em torno dele e aí você chega nos cinco mil, mais ou menos, o que tinha no primeiro ato. E ai vai aumentando, por quê? Porque as 
pessoas têm essa apropriação cada vez mais, tem essa legitimidade do transporte ser um direito, e por mais que isso é uma construção da mídia: de ser uma coisa ilegítima, cada vez mais as pessoas vão se apoderando e vão refletindo, elas próprias sendo cada vez mais os sujeitos dessa luta. E vai aumentando, não sei talvez em grande parte por causa da repressão que dá uma questão midiática, a radicalidade dá uma questão midiática, não sei, acho que as pessoas se apropriaram da luta e isso faz com que elas se interessem mais em lutar. (MILITANTE MPL, 2013)

\section{CONSIDERAÇÕES FINAIS}

Sem ter a pretensão de esgotar o tema, este capítulo busca trazer novos elementos para enriquecer o debate sobre as Jornadas de Junho, que incendiaram no Brasil as discussões sobre o uso da internet nas mobilizações sociais.

Durante as Jornadas, a internet foi utilizada como forma de divulgação de informação e contrainformação, entendida neste capítulo como o uso das tecnologias para contrapor as notícias e dados divulgados sobre os atos pela mídia tradicional. Além disso, muitas vezes a internet, especialmente nas redes sociais, foi utilizada como forma de desmentir a versão oficial divulgada pela mídia tradicional. Assim, é importante pontuar que a internet teve um papel importante nas Jornadas apesar dos próprios representantes do MPL entenderem que esse uso é complementar na atuação do movimento.

Esta linha entre utilizar o mundo virtual para complementar o real e utilizar apenas a internet para mudar o mundo real é tênue. Caso os movimentos sociais não entenderem a internet como um dos instrumentos de luta e não necessariamente como "o" instrumento de luta, consequentemente, terão que reconhecer que sua luta dificilmente obterá ganhos reais:

O problema é quando a fascinação pela Internet e pelas novas tecnologias nos faz esquecer de que o mundo virtual não é o mundo real. As leis, as guerras, a fome, a pobreza, a riqueza, tudo isso se encontra fora dos computadores. Os movimentos 
sociais já existiam antes da Internet, e os meios alternativos, rádios e televisões comunitárias também. As novas tecnologias permitem o acesso à informação por vias mais democráticas e participativas do que as tradicionais. O erro seria que isso produzisse uma fascinação tecnológica que equiparasse os atos de se informar e informar com os de se mobilizar e participar. (SERRANO, 2013, p. 174)

Complementando este raciocínio, já foi dito acerca do uso das redes sociais como elemento acionador dos movimentos que irromperam na Primavera Árabe que:

A mídia nas mãos dos cidadãos pode sacudir regimes. Isso torna muito mais difícil para os governantes manter a legitimidade, controlando a esfera pública. Mas os ativistas, que fizeram tal uso eficaz da tecnologia para reunir adeptos, ainda precisam descobrir como converter essa energia em maior impacto. A questão não é apenas desafiar o poder, é mudá-lo. (TUFEKCI, 2014)

Para o MPL, o aumento do número de pessoas nas ruas foi devido à identificação com a causa do Passe Livre e a compreensão de sua relevância. A questão da repressão ocorrida no ato do dia 13 de junho é lembrada, chega a ser apontada como uma possível colaboradora deste aumento dos participantes nas manifestações. Entretanto, para o MPL, todos aqueles que foram às ruas no ato seguinte à repressão mais brutal, construíram a ocasião para que a mídia alterasse seu posicionamento sobre as manifestações, como elas deveriam ser tratadas pelo governo e pela força policial, e concretamente, conquistaram a redução tarifária do transporte público em São Paulo.

\section{REFERÊNCIAS}

ALLEGRINI, G. O gatilho da revolta: repressão policial, velha conhecida das periferias, surpreende ao atingir classe média. Caros Amigos, São Paulo, n. 196, p. 28-29, jun. 2013.

ATO com 65 mil participantes fecha marginal Pinheiros, em SP, e chega ao Palácio dos Bandeirante. 2013a. Disponível em: <http://noticias. 
uol.com.br/cotidiano/ultimas-noticias/2013/06/17/ao-menos-500omanifestantes-fecham-a-avenida-faria-lima-protesto-segue-em-direcao-apaulista.htm>. Acesso em: 05 set. 2013.

BREDA, T.; BRITO, G. Sem PM, multidões protestam pacificamente e ganham ruas de São Paulo. Rede Brasil Atual, São Paulo, 16 jun. 2013. Disponível em: <http://www.redebrasilatual.com.br/cidadania/2013/06/ sem-pm-multidoes-protestam-pacificamente-por-sao-paulo-6863.html>.

CALDAS, G. O latifúndio do ar: mídia e poder na Nova República (19851989). 2011. Disponível em: <http://issuu.com/encipecom2/docs/ latifundiodoar>. Acesso em: 05 jan. 2012.

CASTELLS, M. et al. Electronic communication and sociopolitical mobilization: A new form of civil society. In: ANHEIER, H. K.; KALDOR, M.; GLASIUS, M. Global Civil Society, v. 6, London: SAGE, 2005/6. Chapter 8. p. 266-285. At: http://www. gcsknowledgebase.org/wp-content/uploads/20056-10-ch8-red.pdf.

COLETIVO DE REGISTRO DA LUTA CONTRA O AUMENTO. $3^{\circ}$ grande ato contra o aumento das passagens em São Paulo. 2013. Disponível em: $<$ http://passapalavra.info/2013/06/78994>. Acesso em: o6 set. 2013. COMITÊ GESTOR DA INTERNET NO BRASIL. Pesquisa sobre o uso das tecnologias da informação e comunicação no Brasil: TIC domicílios e empresas 2013. Coordenação executiva e editorial, Alexandre F. Barbosa. São Paulo: CGI,br, 2014.

CONKLIN, D. B. The Internet, Email, and Political Activism: The Case of Tiananmen Square. The European Consortium for Political Research. In: EUROPEAN CONSORTIUM FOR POLITICAL RESEARCH, 20., 2003. Edinburgh. [Paper] Edinburgh, Scotland, UK, 2003.

EM DIA de maior mobilização, protestos levam mais de 1 milhão de pessoas ÀS ruas no Brasil. 2013b. Disponível em: <http://noticias.uol. com.br/cotidiano/ultimas-105 noticias/2013/06/20/em-dia-de-maiormobilizacao-protestos-levam-centenas-de-milhares-as-ruas-no-brasil. htm>. Acesso em: 19 set. 2013.

ENTENDER as manifestações. Estadão, São Paulo, 15 jun. 2013. Opinião, p. A2. Disponível em: <http://opiniao.estadao.com.br/noticias/ geral,entender-as-manifestacoes-imp-,1042701>. Acesso em: 03 mar. 2016. 
ESPÍRITO SANTO, M. O. Lutas sociais e ciberespaço: o uso da internet pelo Movimento Passe Livre nas manifestações de junho de $2013 \mathrm{em}$ São Paulo. 123 f. 2014. Dissertação (Mestrado em Ciência Sociais) Universidade Estadual Paulista, Marília, 2014.

EVOLUÇÃO da tarifa de transporte em São Paulo. 2013. Disponível em: $<$ http://www.terra.com.br/noticias/infograficos/tarifas-metro-onibussp/>. Acesso em: 06 set. 2013.

FERNANDES, E.; ROSENO, R. de F. Protesta Brasil: das redes sociais às manifestações de rua. São Paulo: Prata Editora, 2013.

GOHN, M. da G. Sociologia dos movimentos sociais. São Paulo: Cortez Editora, 2013.

HARVEY, D. Condição pós-moderna: uma pesquisa sobre as origens da mudança cultural. 15. ed. São Paulo: Edições Loyola, 2006.

HILSENBECK FILHO, A. M. O EZLN e a guerrilha informacional: a política no mundo encantado da mídia e da comunicação. 2004. Disponível em: <http://br.monografias.com/trabalhos914/ezlnguerrilha-informacional/ezln-guerrilha-informacional2.shtml>. Acesso em: 02 jan. 2012.

JUDENSNAIDER, E. et al. Vinte centavos: a luta contra o aumento. São Paulo: Editora Veneta, 2013.

MAGALHÃES, V.; NOVAES, M. SP: fotógrafo do Terra é preso durante cobertura de protesto. São Paulo, 2013. Disponível em: $<$ http://noticias. terra.com.br/brasil/cidades/sp-fotografo-do-terra-e-preso-durantecobertura-de-protesto, 245a815136f $3 \mathrm{f}_{3} 10$ VgnVCM4000009bcceboaRC RD.html>. Acesso em: 19 set. 2013.

MANOLO. Teses sobre a Revolta do Buzu. [2009]. Disponível em: <http:// tarifazero.org/wp-content/uploads/2009/07/por_QS3_RevoltaBuzu. pdf>. Acesso em: 15 set. 2013 .

MILHOMENS, L. MST, esfera pública e ciberativismo: um novo espaço para o debate. Conexões Midiáticas, n. 1, p. 1-11, mar./ ago. 2009. Disponível em: < http://www.insite.pro.br/P\%C3\%Aıginas\%2onovas/ mst_ciberativismo_milhomens.pdf>. Acesso em: 20 dez. 2011.

MORAES, D. de. Comunicação virtual e cidadania: movimentos sociais e políticos na internet. 2000. Disponível em: <http://www.egov.ufsc.br/ 
portal/sites/default/files/anexos/16072-16073-1-PB.pdf>. Acesso em: 28 jan. 2012.

MOVIMENTO PASSE LIVRE. Carta de princípios. 2013a. Disponível em: $<$ http://saopaulo.mpl.org.br/apresentacao/carta-de-principios/>. Acesso em 28 de julho de 2013 .

MOVIMENTO PASSE LIVRE. Apresentação. 2013b. Disponível em: $<$ http://saopaulo.mpl.org.br/apresentacao/>. Acesso em: 28 jul. 2013.

MOVIMENTO PASSE LIVRE. Não começou em Salvador, não vai terminar em São Paulo. In: MARICATO, E. et al. Cidades rebeldes: Passe Livre e as manifestações que tomaram as ruas do Brasil. São Paulo: Boitempo, Carta Maior, 2013c. Cap. 1, p. 13-18.

OLIVEIRA, E. et al. Erica de Oliveira, Gabriel Simeoni, Maurício Carvalho e Arielli Moreira: a tarefa é fortalecer as lutas sociais: jovens que organizaram os atos pelo passe livre falam sobre as maiores manifestações vistas no País. Caros Amigos, São Paulo, n. 196, 16 jul. 2013.

PAPP, A. C. Nas favelas, mais de $50 \%$ de internautas. O Estado de S. Paulo, São Paulo, 30 out. 2013. Disponível em: <http://www. estadao.com.br/noticias/impresso,nas-favelas-mais--de-50-deinternautas-,1091256,o.htm>. Acesso em: 02 nov. 2013, às 18:30.

PIRES, B. Em uma semana, quatro protestos contra o aumento da tarifa em São Paulo. Estadão, São Paulo, 13 jun. 2013. Disponível em: <http:// www.estadao.com.br/especiais/em-uma-semana-quatro-protestoscontra-aumento-da-tarifa-em-sao-paulo,203763.htm>. Acesso em 10 de setembro de 2013 .

RAMONET, I. A explosão do jornalismo na era digital. In: MORAES, D.; RAMONET, I.; SERRANO, P. Mídia, poder e contrapoder: da concentração monopólica à democratização da informação. São Paulo: Boitempo; Rio de Janeiro: FAPERJ. 2013a, Cap. 4, p. 85-102.

RETOMAR a Paulista. Folha de São Paulo, São Paulo, 13 jun. 2013. Editorial. Primeiro Caderno. p. A2.

SECCO, L. As Jornadas de Junho. In: MARICATO, E. et al. Cidades rebeldes: Passe Livre e as manifestações que tomaram as ruas do Brasil. São Paulo: Boitempo, Carta Maior, 2013. Cap. 10, p. 71-78. 
SERRANO, P. Outro jornalismo possível na internet. In: MORAES, D.; RAMONET, I.; SERRANO, P. Mídia, poder e contrapoder: da concentração monopólica à democratização da informação. São Paulo: Boitempo; Rio de Janeiro: FAPERJ, 2013. Cap. 6, p. 145-182.

TUFEKCI, Z. After the protests. The New York Times. The Opinion Pages. March, 19 2014. Disponível em: <http://www.nytimes. $\mathrm{com} / 2014 / 03 / 20 /$ opinion/after-the-protests.html?rref=collection\%2Fcol umn\%2Fzeynep-tufekci\&_r=0>. Acesso em: 14 maio 2015 . 